\title{
How to Improve Information Literacy at School: The Students’ Perspective
}

\author{
Tulio Barrios Bulling \\ Universidad SEK, Santiago de, Chile
}

\begin{abstract}
Information literacy (IL) is gaining importance and recognition as modern society develops. Consequently, it is becoming increasingly vital to initiate its development from very early educational stages. Though students are the main agents of this process their opinions are rarely considered to design and assess IL development programs. This study conducted at a Chilean private school aims to bridge this gap. How do students value their school's IL program? What importance do they attribute to different IL skills? Where and how do they acquire and apply these skills? The main findings evidenced formal and informal learning environments; guided in-class work and solo work seemed to be the main means, and there appeared to be conceptual confusion among IL, computer, and digital skills. Additionally, the current study provides a set of suggestions to enhance IL at the targeted school.
\end{abstract}

Keywords: improvement, information literacy, self-assessment, skills development

\section{Introduction}

The importance of information literacy (IL) within the educational world is increasingly gaining recognition, as many of its aspects and implications directly relate to the teaching practice. Accessibility to information through technological means and mainly the Internet is challenging the teaching of contents. As a result, the development of cognitive skills and IL skills has become a very fertile and relevant research field. Additionally, IL skills closely relate to comprehension and dissemination of knowledge and it is possible to associate them with critical thinking, and other higher-order cognitive skills. IL skills have become a means for life-long learning, and a pathway leading to development, prosperity, and freedom. IL should enable people, regardless of the activities they are involved in, to search, evaluate, use, create, and disseminate information. Accordingly, they may achieve personal, professional, social, and educational objectives. Those who have developed IL skills can access relevant information and take vital and well-informed decisions regarding their lives and future.

In the information society, IL requires all users to possess the necessary competencies to make effective use of information technology and its applications to access and create information. This implies not only technical knowledge about communications and information, but also a clearer understanding of how to use diverse media and formats.

Studies on IL skills teaching and development rarely consider the students' opinions and points of view, at least in the Chilean secondary education. The current study conducted in 2018 at Colegio Instituto Inglés de

Tulio Barrios Bulling, Dr., pedagogue, consultant, educational researcher, and administrator, Faculty of Education and Culture, Universidad SEK. 
Rancagua (CII), Chile aims to bridge this gap.

Being information literate has become necessary in modern society. Consequently, to explore the current state of its development at the selected school is justified. Such an exploration includes the following questions. How does the school conduct IL programs? What IL skills do students consider more important or influential? How do students self-assess their IL competencies? What are the most propitious environments to work on them? What suggestions may they offer?

Additionally, the author aims to provide some recommendations to enhance IL skills and competencies development, based on the findings, the literature review, and his professional experience.

\section{IL in Literature}

Many experts consider IL a significant skill in the knowledge society. Authors usually relate it to the ability of recognising, locating, evaluating, and properly using the needed information. Mackey and Jacobson (2011) went a step further when they proposed to reframe IL as meta-literacy. The authors argued that social media and online communities had created a transcendent, flexible, collaborative, and free-flowing informational and technological environment. Hence, several new concepts related to literacy had emerged. Among them, they mentioned digital literacy, visual literacy, and information technology fluency. Accordingly, Mackey and Jacobson (2011) considered that researchers needed a new comprehensive framework, as traditional definitions of IL were being challenged by these new multiple modalities. In the authors' words, "IL is more significant now than it ever was, but it must be connected to related literacy types that address ongoing shifts in technology" (p. 62).

The authors examined a series of definitions for IL, media literacy, digital literacy, visual literacy, cyber literacy, and information fluency, establishing their similarities and distinctive aspects. However, all of them appeared to be insufficient to account for the current state of affairs.

In this same line, looking for conceptual precision, Virkus (2011) investigated how involved agents, at European higher open and distance learning institutions, developed information-related competencies to contribute to the design of open and distance learning courses with library and IL support. These courses aimed to improve the learners' information-related competencies. The author highlighted the necessity to define IL to study and discuss it. However, the concept was in constant evolution and experts were introducing new concepts to reflect the advances in technology. Thus, the term "IL" had become elusive, so Virkus (2011) preferred to use the concept "information-related competencies" instead, recognizing that the notion "IL" was a useful research constructs covering both information-related competencies and strategic goals.

The author concluded that all the institutions acknowledged the importance of information-related competencies and that the term was widely used; nevertheless, many involved agents misunderstood its meaning. Some evidence suggested that teachers, in collaboration with the librarians, delivered some information-related competencies in their courses. Notwithstanding, a solid framework to guide and register the whole process did not exist.

Also, looking for conceptual precision, Weiner (2011) presented another work. He aimed to explore if there were differences between critical thinking and IL. He found that IL and critical thinking had much in common and that the former had been the study object of academic librarians, while the latter the focus of faculty discipline specialists. The author summarised the differences in two dimensions: the degree of formalism and learning behavior employed. The former associated with cognitive processing (private) and the latter with delivering information (public). 
Weiner (2011) proposed to integrate the strengths of each model to create and develop a more effective curriculum and set of actions. From IL, one could take the identification and retrieval of relevant documents, and from critical thinking the expansion of the cognitive processes to all fields, including IL.

In 2012, the Association of College and Research Libraries (ACRL) revised an already approved document that constituted a guideline for IL programs. As they wanted to illustrate best practices, this guideline intended to articulate elements of exemplary programs. The authors aimed to help professionals who wanted to develop, assess, and improve IL programs. They declared that the characteristics listed were not prescriptive and that agents should consider them within the institutional context.

Peter, Leichner, Mayer, and Krampen (2015) offered a new vision of IL instruction efficiency by relating it to providing individual feedback. They began their study under the premise that all students had strengths and weaknesses, and only a few of them were consistent literate users. According to the authors, this situation led to two new challenges: how to deliver instruction in a time-efficient way, and how to design instruction programs to cope with individual differences.

Computer-based instruction would help to make this instruction method possible. The authors introduced an approach to IL instruction, where instructors comprised online learning and one classroom seminar. The former imparted most of the content, while the latter served to reflect the online material and to practice.

As expected, the students showed fragmented knowledge and their strengths and weaknesses. Consequently, the authors matched instruction to individual differences following a remedial strategy. They hypothesized that "those participants who completed a chapter should achieve a higher gain on those items of the test that are assigned to the relevant chapter than those participants who did not complete that chapter" (Peter et al., 2015, p. 1137). The authors expected that students who completed more chapters would show more learning progress than those who did not.

Peter et al. (2015) concluded that the hypothesis proved to be valid and that a blended teaching approach could be efficient when adapted to the users' needs by providing customized feedback.

IL teaching was the topic of Burkhardt's (2016) work. She intended to make the Framework for Information Literacy for Higher Education more understandable and to imagine how instructors might help students cross those thresholds. Additionally, she wanted to set some focus on determining how memory and learning transfer might apply to IL teaching. A third aim was to provide some recommendations about how to design effective IL instruction programs.

In the author's opinion, the referred "framework" presented some limitations one needed to face:

(a) proving its actual usefulness;

(b) lacking practical information;

(c) filling individual instructors' gaps;

(d) determining how to "dress" the "framework"

(e) Librarians, instructors, and administrators working together in creating a program for every subject and every level;

(f) designing a roadmap to follow;

(g) providing instruction to educate a literate person;

(h) making the six threshold concepts easy to understand.

After finishing her critical analyses, Burkhardt (2016) provided a series of ideas that might help to develop new strategies or approaches. For example, taking the students from the familiar to the less familiar to the 
unfamiliar; making the students mentally stretch to make a lesson more memorable; selecting and applying crucial information; getting the students to think about the consequences of plagiarism; expanding the role of the individual in the information world; and applying the same skills to the "real world."

To conclude, the author affirmed that students had to learn concepts and skills that helped them to become information literate citizens by making students active participants in their learning processes. Discussion, exploration, challenging questions, ethical issues, and social inquiries were some good means to do so.

Innovation in IL research was also a topic that captured Bruce, Demasson, Hughes, Lupton, Abdi, Somerville, and Mirijamdotter's (2017) attention. They introduced the relational approach to IL, on which they based some theoretical innovations. The authors considered the relational approach a concept that comprised different manners to think about IL, IL research, and IL education. They based their approach upon understanding variation in people's experience of that phenomenon. Hence, the idea of "information experience" was deeply associated with "learning experience” as key elements of the IL experience.

The conceptual innovations considered inclusive informed learning, informed systems, expressive windows, spaces for informed learning, information experience design, informed learning design, cross-contextuality, and experience identity.

That same year, Corrall (2017) presented a reflection about IL development. She asked whether practitioners thought enough about what they were doing, and she aimed to review the concepts of reflection and reflective practice and their professional applications.

The author argued that practitioners should use reflection to enhance practice and make it more effective. Besides, she stated that the reflection process could be highly challenging, as some in-context involved agents might need reference models. Reflection exercises may be individual or collective; either way, it was important to pay attention to the local community, since it would provide the right context to make the reflection process more meaningful.

Corrall (2017) identified the following outcomes: learning for further reflection, action, critical review, reflection on the process of learning or functioning, the development of theory, self-development, decisions or the resolution of uncertainty, empowerment, and emancipation, other unexpected outcomes that may offer some solutions, and feeling, emotions or knowledge about them. The mere possibility of obtaining influential outcomes made the reflection process worthwhile.

According to the author, some researchers approached the reflection process from its nature, being technical, descriptive, dialogic, critical, and contextualized. Others considered the role of the individual who reflected. For instance, reflective person, reflective technician, reflective professional, and reflective citizen.

After having seen how both educators and practitioners had observed benefits from using reflective journals and other tools at an individual and organizational level in a range of practice contexts, including subject liaison, information literacy instruction, and leadership development programs (Corrall, 2017, p. 34).

The author seemed convinced that reflection should enhance not only professional development but also the teaching role of librarians and the learners' support. Nevertheless, there were still some obstacles to overcome: limited commitment, inadequate preparation, lack of support, need for further guidance, few tools and methods suited for each reality.

Elmborg (2017) presented a contribution based on a 40-year long career as a literacy educator. For the author, literacy was the key to face and succeed in changing environments. Literate people had learned to learn. 
Therefore, they were able to adapt rapidly, to take new roles, to access the information needed, to assemble new knowledge, and to apply it to creatively solve new problems or demands.

During his career, Elmborg (2017) found his focus on literacy, rather than on teaching. He referred to "narrative literacy" as a concept to track the development of IL from his personal history. The author considered himself the product of some sort of literacy instruction where students should become good writers by reading and imitating well-known and highly recognized authors. This situation began to change in the seventies when experts started to focus their attention on the internal processes, considering writing a cognitive process.

At that stage, Elmborg (2017) reported to have avoided repeating the instruction model he suffered, so he taught using a rhythmic structure and a sequence of sessions supported on brainstorming, drafting, revising, and editing. For the author, the writing was a meaning-making process and not just a simple knowledge report.

The relationship between the library and the writing process was another relevant element the author identified. Traditionally, librarians conducted bibliographic instruction sessions, which the writing process movement challenged. This produced a significant conversion in library instruction, and the first studies about library research processes appeared.

The discovery of the Internet motivated Elmborg (2017) to "re-think the nature of academia, the ways we access and communicate scholarship, and the ways authorship would have to change in the context of the emerging new world” (p. 59). Additionally, the new century introduced main themes to the discussion: IL, the social turn, pragmatic approaches to IL instruction, and assessment.

Finally, the author expressed his concern about the ways global leadership had made the new economic order seem natural, and about the great influence, that neo-liberalism had on modern society, literacy education included.

The changing contexts and enduring challenges were the themes of Fister's (2017) paper. Like Elmborg, the author did a personal exploration of IL, based on her experience in the field. She initiated her account describing the changes society had suffered in the last two decades. Her goal had always been to offer students an integral education through IL that allowed them to succeed and influence the world. In her opinion, that goal still stood, although the forms had been altered. Nevertheless, what remained unchanged was the deep learning students need to experience, regardless of the form.

The author reported that she used her experience as a map to cover three identified periods: the age of bibliographic instruction, the age of the IL standards, and the age of critical IL.

From the first age, she recalled having been responsible for educating her community in the new electronic catalog. Moreover, she reported having fought decidedly for an enhanced and truly acknowledged role of the librarians. When the standards made their way in the literacy community, Fister (2017) remembered an enthusiastic reaction to them, which many of her colleagues did not share. The main complaint was that the standards did not explain what being able to find, evaluate, and use information ethically really meant in practice. Another area of discomfort was the long list of measurable performance indicators and outcomes.

In the following years, the author discovered that many librarians had assumed an unquestioned standardization of IL and that they had become a sort of meaningless library rules, which was not the transformative experience she wanted. To cope with this situation, she initiated a project to help students cross the IL thresholds. Though librarians had common ground for discussions, the author learned that IL literacy to be a truly joint venture needed to include the faculty in the debate. 
Todd (2017) also identified some challenges and opportunities regarding future directions and developments in IL. After years of studies, the author called for a meta-analysis to satisfy still existing necessities. In his words: "Our IL field needs some kind of cogent meta-analysis, to establish some powerful claims about the effects and outcomes of IL instruction. This to me is the missing piece” (p. 129). Literacy instruction should develop intellectual agency, social agency, and personal agency. For the author, this was the focus the field needed, one based on strengths, not on deficiencies. Todd suggested that the collection of propositions should develop a met theory of IL. This would enhance discourse and practice, and strengthen IL position in different forums.

Regarding IL, Todd (2017) affirmed that there was not enough exploration of that particular aspect. This represented a deficiency that one should solve. The librarians' educational qualifications to deliver instruction were another challenge he identified.

The author called for a disciplined debate about IL conceptions and practices. He perceived a need to develop an understanding of IL from various perspectives and theoretical approaches, and to develop research leading to professional frameworks that accounted for this diversity. A deeper understanding of meaningful pedagogies for IL instruction, the true implications for enhancing the instructional capacities of librarians, the intersection of learning theory and other theoretical approaches, conceptions of information and knowledge, research results, and life-centered outcomes should become the main concerns for the future of IL, according to Todd (2017).

One may conclude that IL is a concept in constant evolution; consequently, it is difficult to define and fully comprehend. Key terms, such as "competence" and "skill” are sometimes used as interchangeable synonyms or oppositely, as very different concepts. Something similar happens with the term "information literacy"; formed by two complex words, with no agreed meaning making it difficult to define.

What seems to be well established is that IL is more than technology and that being computer literate is not the same as being information literate. The second concept is supposed to be broader conveying deeper implications. As a result, many authors claim for terminology precision and better-defined boundaries between skills and competencies. Also, the IL literature introduces new concepts, such as meta-cognition, meta-literacy, and thresholds.

\section{Design and Development of the Research}

The author researched using a mixed-method approach, applying quantitative and qualitative methodologies. A survey to obtain a broad vision of the study object, and personal semi-structured interviews to gain a limited yet more in-depth understanding.

\section{General Objective}

To explore the state of the art of IL at CII from the students' perspective.

\section{Specific Objectives}

1. To understand how students evaluate IL skills;

2. To determine which IL skills students value the highest;

3. To provide some recommendations to develop IL skills systematically.

\section{Context}

The researcher conducted the study in 2018 at CII, Rancagua, Chile. This school is located in the city of Rancagua, 100 kilometers South of Santiago, Chile’s capital city. It is a traditional coeducational private K-12 
school with matriculation of about 1,200 students. It offers an integral education with a strong emphasis on the teaching of English, sports, and extracurricular activities. Although secular, CII has a Christian orientation.

\section{Sample Constitution}

For the quantitative data collection, the author applied a voluntary survey to students who were about to finish their 12th and final grade. Furthermore, at this stage, they were more mature and experienced, embodying the educational project final profile. Fifty-two students volunteered to be part of the study. For the qualitative information gathering process, the author interviewed six students on a voluntary base, respecting gender parity.

\section{Data Processing for Its Study and Analysis}

As the research considered a mixed-method approach to gather information, the author applied different analyses models. For the quantitative analysis, the researcher processed the data collected via a survey in an Excel spreadsheet. He determined arithmetic averages and other central tendency measures, trend measures, hierarchies, and ordinances. Besides, he generated the corresponding graphs. The qualitative analysis considered interviews transcription and processing by using the AQUAD 7 sofware for qualitative and quantitative text analysis.

\section{Quantitative Findings}

In this section, the author will describe and discuss the information in a quantitative numeric manner.

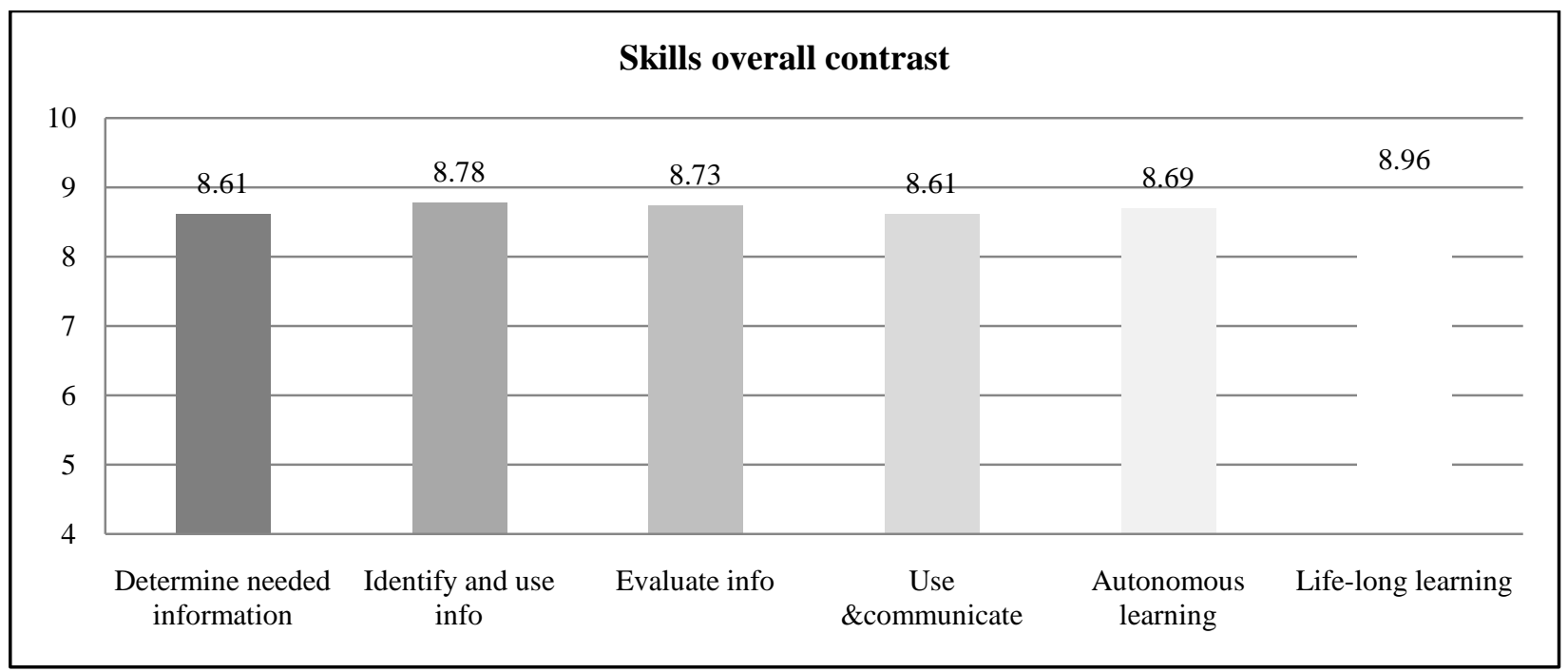

Figure 1. Graph skills overall contrast.

\section{Self-Assessment of IL Skills}

Figure 1 helps us realize that all skills were highly self-assessed by the informants, the life-long learning skills obtained the highest average score: 8.96 points. The skill to identify and effectively use potential information sources took the second position with 8.78 points. In third place, one could find the skill for evaluating information under some given criteria (8.73 points), closely followed by autonomous learning with 8.69 points. There was a perfect 8.61 points draw between the skills for determining needed information and using and communicating information in the last position. 


\section{How and Where IL Skills Were Developed}

In this section, the students reported how and where they developed their IL skills. Figure 2 shows the summation frequency of the informants' answers. Two different environments obtained the highest frequency: solo work at home and guided work in the classroom. In other words, students mentioned formal and informal education settings 41 times each. They considered free work at the library 32 times, followed by work with friends or relatives, which students reported 28 times. Informants mentioned free work in the classroom on 23 occasions. Guided work in the library, work at the computer lab, and other not contemplated places, obtained lower frequencies: 17 , nine, and two, respectively.

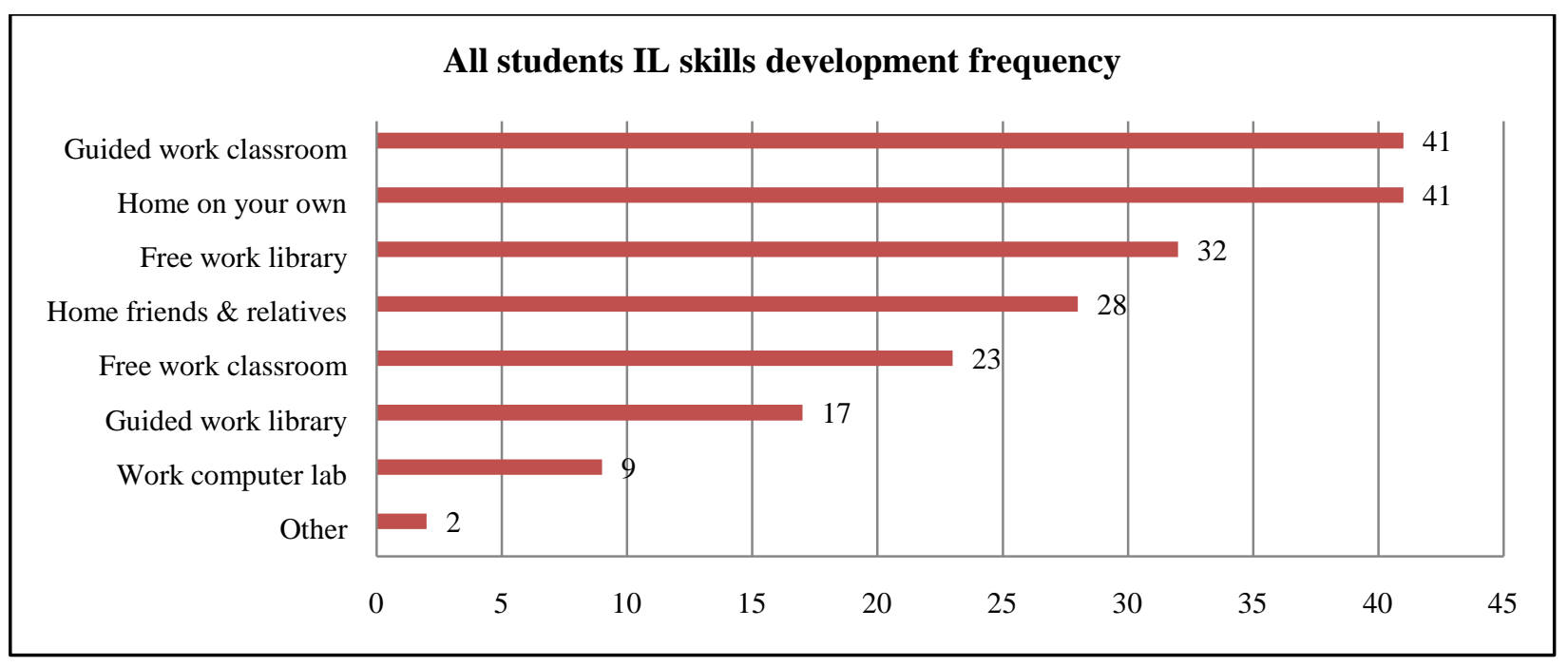

Figure 2. Graph all students IL skills development frequency.

\section{Skills’ Importance}

In this final section, the informants ranked a series of skills from one to six according to the importance they considered they had. Consequently, in terms of the current analysis, the lower the summation, and the higher the attributed importance.

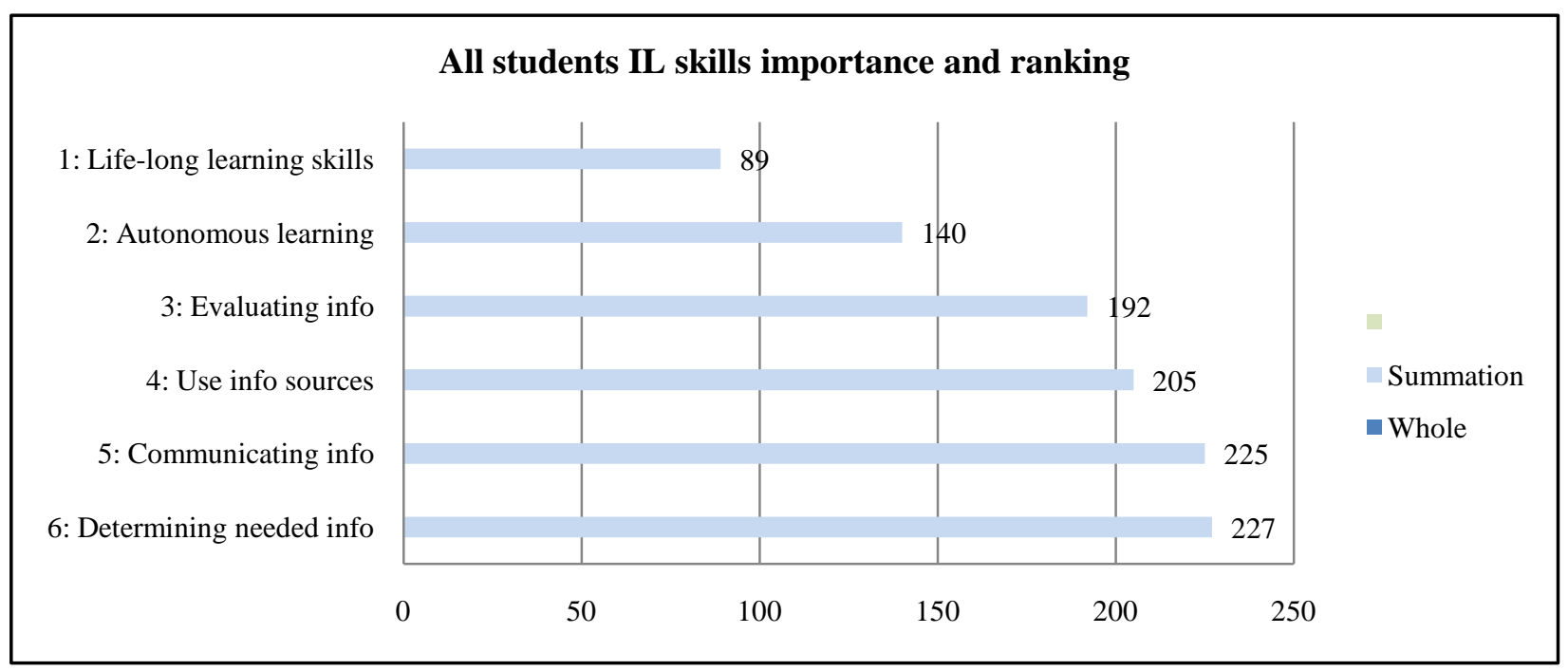

Figure 3. Graph all students IL skills importance and ranking. 
Figure 3 illustrates that, for the whole sample, life-long learning was the most important skill. Autonomous learning occupied the second position, followed by evaluating information in the third position. The next three skills were all very close, the use of information sources ranked fourth, communicating information fifth, and determining needed information obtained in the last position.

\section{Qualitative Findings}

Here, the author presents and discusses the qualitative information gathered via interviews. Firstly, he will present a code frequency graph to proceed with a code-to-code analysis. To ensure confidentiality, the researcher randomly assigned numbers to the students.

\section{Code Frequency Analysis}

The author had to use code IL class work (ILCW), associated with in-class work, 36 times. It was the students' recurrent topic, followed by the 29 mentions to code IL general knowledge (ILGK), and related to general knowledge. Code IL skills specific importance (ILSI) totaled 23 references, while code IL importance (ILIM) 20. Codes IL self-assessment (ILSA) and IL students' suggestions (ILSS) presented lower frequencies, 11 and nine, respectively.

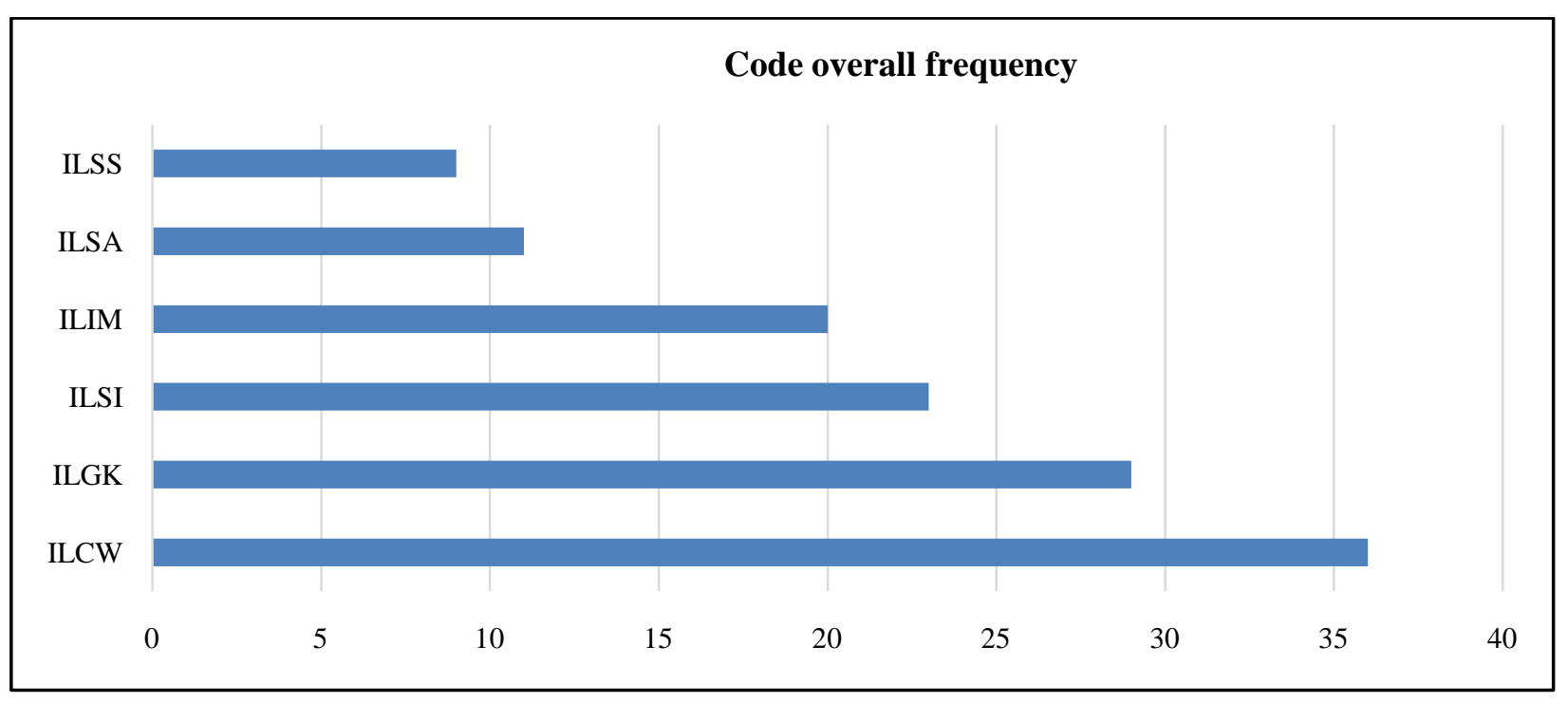

Figure 4. Graph code frequency analysis.

\section{Code ILCW: In-Class Work to Develop IL Skills}

Students 1, 3, and 6 were able to describe activities related to IL skills development techniques. They identified subjects (History and Language) and spaces (classroom and library). Looking for information, summarising, developing projects, and understanding were some of the reported activities. Student 2 stated that there was no subject directly associated with IL skills since they did not have computation as a subject anymore. Student 4 mentioned that she has never heard about IL skills, which is strange, as all informants knew what the interview consisted of. Maybe she got confused or her teachers did not make explicit reference to these skills when they worked on them. Finally, Student 5 associated IL skills development with information technology and digital infrastructure rather than to methodological procedures. Some answers denoted a blurry line between IL skills and technological competencies. 


\section{Code ILGK: IL Skills General Knowledge}

This was one of the most extensive themes during the interview. All informants provided descriptive answers about IL skills use and familiarity. Once again, there was a mixture of technological competencies. Students frequently mentioned the skill for searching and selecting information. They also referred to understanding data and news, as well as problem-solving and relating main topics to subject matters or contents. The use of Google, Wikipedia, and the basic office package was also informed.

\section{Code ILIM: Importance Given to IL Skills}

All students considered IL skills important, though their reasons may vary. The students' answers evidenced this mixture of IL skills and technological competencies that the author has already discussed. For students 1 and 5, they were part of the contemporary world. Besides, technology would facilitate work and be useful in all sorts of trades. For students 2, 3, and 6, they helped to access information. This information would increase their knowledge and culture and would help them to have topics to share and a basis to understand others. Finally, student 4 considered that IL skills helped her to enhance reading understanding.

\section{Code ILSS: Suggestions to Improve IL Skills Development}

The interview also searched for suggestions to improve the IL skills development at school. All of them were sensible and constructive. Students 1 and 2 believed that educators should initiate the IL skills development process in the early years of instruction. The earlier you started the easier should the development process be. Students 3 advocated for relating skills development to grades. As a result, students would take IL skills development more seriously.

Student 4 included suggestions related to emotional aspects, such as motivation and involvement, which would mean guiding students to understand and value IL skills development. Student 5 evidenced a more holistic approach when she proposed relating IL skills development to every aspect of the school's operation. The recommendations of Student 6 considered a personalized teaching approach, paying special attention to students who presented some difficulties.

As one may realize, the students' responses covered a vast spectrum of the teaching process and the school system.

\section{Code ILSA: Students' Self-Assessment of the IL Skills Development or Command}

The students self-assessed their IL skills well. Some gender distinction, all three male students considered themselves well prepared, while only female Student 5 declared feeling prepared but only at a basic level. Students 4 and 6 reported not feeling yet on command. Most students' related their answers to computer use rather than to IL skills development. Additionally, three of them associated IL learning with both school and home. Two students reported a close relationship between IL skills and reading comprehension. Both felt weak in the latter.

\section{Code ILSI: Degree of Importance Given to Specific Skills}

When asked for specific skills importance, the answers were much more accurate and precise. Knowing how to obtain information was the most important skill. Student 1 complemented it with the capacity to select it in terms of relevance. Student 2 provided an almost perfect sequence of IL skills work out, while Student 3 added talking about the needed information as another important ability. Student 5 also related the importance of the skills to information processing. In her perspective, identifying sources and determining correct 
information were crucial competencies. Students 4 and 6 associated the skills' importance with comprehension and other associated processes, such as relating, summarizing, and applying data.

\section{Conclusions}

Students seem to develop their IL skills in both formal and informal environments. They frequently mentioned guided work in the classroom and solo work at home. This situation conveys deep implications for teaching and learning. Teachers must assume that school is no longer the only environment where students learn. Consequently, they should be able to deliver some guidelines to orientate work, study, and IL skills development at home.

The research showed an overall conceptual confusion or mixture of terms that informants used indistinctively, but that the revised literature suggests they are not equivalent. Informants tended to confuse IL skills, digital and technological competencies, and computing capabilities. Doubtless, technology may be of great help. Notwithstanding, IL is much a broader concept. Similar confusion became evident when informants related their IL skills' development level to the command of programs, such as Word, Excel, and PowerPoint.

In general, male students felt better prepared than their female classmates did. Probably, a good topic for further research, as this investigation did not aim to explore eventual differences associated with gender.

As happened during the quantitative analysis, students also identified formal and informal environments as adequate places for IL skills development during the interviews. This evidences a good degree of consistency among the data collected through both methods. The growing importance of learning outside scholastic environments creates new challenges for teachers and their practice.

\section{Suggestions and Implications}

This section starts with the students' recommendations. Some suggestions related to timing stated that students should initiate the IL skills development process from very early stages. One would certainly recommend this since all processes related to skills development take a long time to consolidate and prosper. Another student suggested associating IL skills development with grades, as a means to encourage students to take their acquisition and development more seriously. To provide IL skills development, a formal context may be advisable, notwithstanding, students should be aware of their importance beyond the impact they may have on their grades.

Some students proposed to relate IL skills development to some affective factors, which seems adequate, considering that the affective domain has a direct impact on both interest and motivation. Some suggested a personalized follow-up approach that helped prevent leaving slower students behind. This is certainly a pedagogical proposal, since learning rhythms are different, and the school system should be able to assist all students with different learning styles.

One can also find some common ground in the students' proposals, in the generalized opinion that the school should teach IL skills. Though the survey evidenced that most students acquire their IL skills at school and home, they seemed to be quite conscious that they also needed formal instruction. This suggestion has clear programming and methodological implications that the school has to analyze and consider.

The interviews suggested a lack of conceptual precision. Students used concepts related to IL, technological information, and computing skills and competencies indistinctively. To gain conceptual precision and a systematic approach for developing IL skills at CII, one may suggest to adopt one of the existing IL 
frameworks and to adapt it to the local reality. An IL framework would provide enough background to generate a program suitable for the school's needs and the Chilean curriculum.

The school community could summon a committee to develop such a program based on the broad existing literature. Hence, they could generate conceptual definitions, standards, learning dimensions, and outcomes and share them with the school's community.

Another challenge CII should face is the role of each involved agent. As informants reported that teachers developed IL skills in the classroom, computer lab, library, and at home; the school should specify the roles and responsibilities of all participants. Time and space for developing teamwork and collaborative efforts are also essential. Most successful experiences attribute high importance to systematic collaboration and understanding, mainly between teachers and librarians. A broad consensus should facilitate the recognition of the educational role of the librarians and the importance of IL skills development, narrowing the gap between class work and work at the library. Determining the pedagogical implications of IL is another task the school has to undertake.

One should also consider some methodological teamwork issues. To begin with, by setting demanding but affordable goals, determining the levels of needed information, and using knowledge to enhance intelligence. Additionally, to foster understanding, the involved agents should link IL skills development to higher-order thinking skills, such as analysis, synthesis, and evaluation. It would also be prudent to integrate IL into subject areas. This would allow teachers and students to work with them in a more concrete and applied manner. Some sound recommendations for IL skills development would be to work on them in real contexts, both in an individual and collective manner. It would also be relevant to conduct diverse methodological activities that could cope with all the students' learning styles and preferences. As the author has already referred to, IL skills development also occurs in informal contexts or situations. Consequently, it would be convenient to provide the students with some guidelines to help them conduct their processes. Especially, as far as critical thinking is concerned.

The school should also attempt to relate IL to reading and writing. Reading fosters understanding and critical thinking while writing deals with creating and communicating information, ideas, or feelings.

Another sound suggestion is that an IL program also requires some assessment policies. How are the agents going to assess the students' advances? Who is going to be in charge of the evaluation process? How are teachers going to provide feedback? How are they going to support students in deficit?

The final proposition relates to some administrative issues. Developing an IL program implies having the necessary resources to ensure access to information sources, getting appropriate software, and counting with the right equipment. Human resources are even more essential. Teachers have to receive the proper training, guidance, and support. Access to expert advice would also be desirable.

\section{Limitations}

The current research conveys two main limitations: The researcher conducted the survey and interviews in Spanish, so some nuances may have been lost in translation. The specific context where he inquired makes it difficult to generalize the results.

\section{Recommendation for Further Research}

The methodological implications of an IL program development may offer interesting possibilities for further research with a direct impact on the teachers' and librarians' daily practice. What strategies do involved 
agents use for IL skills development? How do they interconnect them among subjects and grades? How do teachers support left-behind students? How do IL skills affect students’ and teachers’ learning?

\section{References}

Association of Colleges and Research Libraries. (2012). Characteristics of programs of information literacy that illustrate best practices: A Guideline. Retrieved September 10, 2017, from http://www.ala.org/acrl/standards/characteristics

Bruce, C., Demasson, A., Hughes, H., Lupton, M., Abdi, E. S., Maybee, C., Somerville, M. M., \& Mirijamdotter, A. (2017). Information literacy and informed learning: Conceptual innovations for IL research and practice futures. Journal of Information Literacy, 11(1), 4-22.

Burkhardt, J. M. (2016). Teaching information literacy reframed. Chicago: Neal-Schuman.

Corrall, S. (2017). Crossing the threshold: Reflective practice in information literacy development. Journal of Information Literacy, 11(1), 23-53.

Elmborg, J. (2017). Lessons from forty years as a literacy educator: An information literacy narrative. Journal of Information Literacy, 11(1), 54-67.

Fister, B. (2017). The warp and weft of information literacy: Changing contexts, enduring challenges. Journal of Information Literacy, 11(1), 68-79.

Mackey, T. P., \& Jacobson, T. E. (2011). Reframing information literacy as a metaliteracy. College \& Research Libraries, 72(1), 62-78.

Peter, J., Leichner, N., Mayer, A. K., \& Krampen, G. (2015). Making information literacy instruction more efficient by providing individual feedback. Studies in Higher Education, 42(6), 1110-1145.

Todd, R. J. (2017). Information literacy: Agendas for a sustainable future. Journal of Information Literacy, 11(1), $120-136$.

Virkus, S. (2011). Development of information-related competencies in European ODL Institutions. New Library World, January, $1-14$.

Weiner, J. M. (2011). Is there a difference between critical thinking and information literacy? A systematic review 2000-2009. Journal of Information Literacy, 5(2) 81-92. 